\title{
Research on the Application of MOOC in College English Basic Teaching
}

\author{
Yaping Wu \\ Xijing University, Xi'an City, Shaanxi Province, China, 710123
}

Keywords: Application, MOOC, College English Basic Teaching

\begin{abstract}
In the global MOOC era, domestic and foreign colleges and universities withdraw from the Internet independent learning model of the research boom. This paper analyzes the current situation and existing problems of basic teaching in college English and discusses the influence and reference of MOOC concept and technology on college English basic teaching mode, and expounds the new teaching mode combining MOOC technology with classroom teaching.
\end{abstract}

\section{Introduction}

With the rapid development of network information technology, MOOC because of its high quality free online open educational resources and quickly spread to every corner of the world, to the traditional higher education has brought great challenges and shocks. At present, there are more than 60 colleges and universities in China have opened MOOC courses, but for the development and application of MOOC resources research is not much, for MOOC resources in Chinese college English teaching application research is even rare. At present, no master's degree thesis and doctoral thesis similar to this thesis have been found. In the MOOC era, college English teaching is facing unprecedented challenges and challenges. College English teachers should seize the opportunities brought by MOOC, strengthen the development and application of MOOC resources in college English, and actively seek exploration and breakthrough in teaching mode. We draw on the MOOC educational philosophy, college English teaching in addition to imparting basic language knowledge and general skills, but also to develop students' academic English ability and cross-cultural communication skills.

College English teachers should dare to try new things, through learning and imitation demonstration MOOC teacher class, etc., to experience the advantages and disadvantages of network courses, play MOOC advantage and enhance their own business level and ability to teach. Before learning the new learning model, we should choose the appropriate learning materials and learning content for the educational objects, and lay the foundation for the future high-quality classroom teaching.

College English teachers are increasingly concerned about the MOOC-based hybrid teaching model development, keen on "micro-class", "flip classroom" design and production. On the one hand, teachers are required to master the production of micro-video methods; the other hand, higher education departments and colleges and universities to actively organize micro-video experience technical seminars. To discuss the micro-video in the creative process, the teacher can each of the knowledge points are vividly taught out, whether the focus, difficult to have a very clear understanding of the course content and its internal relations for the perfect division, but also by The impact of the widened student questioning, which poses a great challenge to the instructor, and a higher demand.

College English application MOOC teaching, students from the national college English course network platform elective courses in the school to accept the English teacher's curriculum Q \& A, the university teachers also need to set up according to their own special questions and answers lessons to help students complete the English course. College English teachers should actively try to play the role of instructors in the students' self-study after class, to provide students with timely online learning help and suggestions so that students can grasp the correct direction of English 
learning in MOOC platform and achieve the optimization of learning effect the college English teachers should focus on the integration of the latest English teaching materials, develop a sound teaching plan and combined with different professional composition MOOC research group, pay attention to the MOOC content of the capacity of moderate and interactive, for different students of the English language learning classification guidance.

\section{MOOC}

MOOC is the English acoustics of Massive Open Online Course, which means that large-scale network open online courses. MOOC is the new development of distance education, only an initial form of online education, but also has great prospects for development. China will MOOC transliteration for the "Mu class" is the first person in Nanjing Normal University Professor Jiao Jianli. MOOC produced a shorter time, 2012 is known as the "World MOOC first year" 2013 was called "China MOOC first year." MOOC is currently seen by the famous universities at home and abroad by the professor of free online open class.

\section{MOOC Development and Application-Related Theory}

The rapid development of MOOC is based on the idea of lifelong education and the idea of democratic equality. MOOC's theoretical basis is mainly constructivist learning theory and Unicom learning theory. Whether it is based on the MOOC of the constructivist learning theory or the MOOC based on the theory of Unicomism, we can combine the interchange and the distinction between the interchange and the difference, so that the learners can be associated with each other in the network The knowledge system and interpersonal relationships to build their own new knowledge system.

Unicom Learning Theory. George Simmons argues that the existing learning theory cannot explain the basic characteristics of learning in the network environment, thus proposing the online learning theory based on the network environment [1]. Unicom is focused on individuals and it believes that personal knowledge can form a network to support the individual's continuous learning and development. Unicom provides an ideal model for people to learn in the information age. Based on the concept of Unicom, MOOC platform network courses can be the world's learners learning experience together, in order to obtain more wisdom and knowledge. Knowledge is the process of changes in the flow of knowledge such as the flow of oil in the pipeline, and the pipeline is the node of knowledge of China Unicom; Unicom training and maintenance of this process is inseparable from the study, and learning the starting point is personal, personal knowledge The system constitutes a network in which learners can communicate and learn spontaneously, and then feed back to the personal network to support individuals to continue to deepen their knowledge. At the same time, teachers in accordance with the requirements of the times and timely adjustment of teaching content, teaching objectives and teaching methods, such as traditional teaching, the classroom involved in some of the memory or recitation of the relevant knowledge can be directly searched in the network.

Constructivist Learning Theory. In the early 1970s, educators put forward the constructivist learning theory based on cognitiveism. Piaget suggested that in the process of cognition, the learners were originally analogical and visualized, then understood and accepted new knowledge, and sought the relevant balance between knowledge. The core of constructivist learning theory is that learning is a constructive learning activity that learners build on their own knowledge and experience. Learners based on social and cultural background, the existing experience and other learning methods, through a variety of necessary learning resources, in the internal initiative to build relevant knowledge. Constructivist learning theory that the knowledge taught by teachers is not a convention, not to understand the knowledge of teachers as students absorb the standard of knowledge, with the authority of teachers to dominate the students to learn. Learning is the process of building students' knowledge, based on their own background and experience, to analyze knowledge, understand knowledge, acquire knowledge, and test and criticize new knowledge. " 
Audiovisual Education Theory. In 1946, American educator Edgar Dale in the "audio-visual teaching method," a book put forward the theory of audio-visual education. This has become the theoretical basis of MOOC to promote the reform of college English teaching mode and improve the quality of college English teaching. In 1960, psychologist Tereira said: Under normal circumstances, people can remember to see, hear 50\%, which is much higher than the pure look, read and write. English learning is a process from mastering language knowledge to proficiency in language skills. Therefore, the study of English learning is through the role of alternative bridge and through a large number of learning practice, so that students master the language knowledge, the formation of language skills, but the basic task of English teaching.

\section{The Application Strategy of MOOC in College English Basic Teaching}

Changing the Educational Philosophy to Enhance the Teachers' Information Technology Level. The educational concept of the Internet age should be combined with practice, centered on students' interests rather than teachers. MOOC development environment, the traditional instructional teaching model has become an auxiliary learning service, teachers' "dominant" role in the conversion and teachers need to have a diversity, multi-disciplinary areas of knowledge to enrich themselves, to achieve the role of transformation, In order to be able to carry out effective teaching and guidance work in a large number of emerging media situations. College English teachers should have the ability to master the "technology" and "teaching design and implementation", with MOOC, students can accept the most cutting-edge to maximize the information, the teacher is to do "to the fishing", provide a variety of English learning resources and encourage students to actively use these learning resources: organize a variety of lively classroom activities, play the initiative of students in the initiative; to help students plan English learning, better implementation of practical learning programs and goals and so on.

Explore the Mixed Teaching Model and Enhance the Curriculum Adhesion. MOOC is not omnipotent, should try to apply new teaching style in curriculum design, limited by teachers' ideas, teaching habits, information literacy and concerns about the quality of online learning and other factors, O2O mixed mode is still the main direction of our university. MOOC's learning is not man-made to monitor and drive, learning depends on the learner's self-regulation; learners spontaneously communicate, collaborate, establish a connection and build a learning network. Learners carry out interactive learning based on a variety of social media (such as discussion groups, micro-blogging, social labels, social networks, etc.), through the sharing of resources and multi-angle interaction to expand the scope of knowledge; through communication, collaboration, Construct new knowledge through different cognitive interactions within the community. Therefore, if the motivations of MOOC learners are not solved by the current curriculum model, the "stickiness" of learning is difficult to maintain and the rate of completion becomes very difficult. MOOC era, the traditional teaching model has been difficult to deal with these changes. To meet the new requirements of society and students, to further promote the development of college English teaching, teaching model reform is clearly imperative. We should form a "MOOC model + classroom discussion" of the mixed teaching mode. Mixed teaching model can take into account the popularity of knowledge and innovation, the full realization of the university's educational functions.

Increase Publicity Efforts and Encourage Learners to Actively Participate. In view of the fact that many learners are not aware of MOOC, learner participation is a comprehensive experience of MOOC learning, and has a great influence on the perception of usefulness and ease of use. Only by studying the physical experience of MOOC, learners will really understand their usefulness and ease of use. Teachers can encourage students to study the relevant MOOC, or actively consider the MOOC into the classroom, such as the attempt to flip the classroom. Schools can introduce lectures and other ways to introduce MOOC, so that more learners in-depth understanding of MOOC platform and curriculum to enhance the acceptance of the level of English MOOC. But also increase the number of forums, through the establishment of QQ group, micro-credit groups, etc., to increase MOOC education model of propaganda. These social software 
is easy to land, broad audience, spread the information quickly, through a similar platform to push MOOC reminder information to attract potential learners to join the relevant courses early in the study.

Encourage learners to participate. Teachers can encourage students to understand and learn English MOOC and you can also consider the introduction of MOOC into the English classroom such as exploring college English flip classroom teaching mode or micro-class teaching mode. At the same time, the learner is given a certificate, credit certification, scholarship or other incentives to encourage learners to participate in MOOC study. So the study of outstanding or outstanding performance of the learners can get material incentives or spiritual support. Teachers should also pay attention to the learners' learning motivation, including learning motivation, including interest.

Building a Harmonious Relationship between Teachers and Students to Promote Interaction between Teachers and Students. In view of the lack of emotional problems in the teaching model of college English MOOC, college English teaching should focus on the teaching of "teaching" and "learning" to strengthen the teaching reflection and evaluation. Teaching and learning, teachers and students interact, to build a harmonious relationship between teachers and students. MOOC to learn the main, to break the traditional teaching to teach the main teaching model, you can teach each other. Emotion and cognition are two basic dimensions of learner participation in learning. Positive emotions will give learners the motivation and persistence of learning. On the contrary, negative emotions will not only affect the normal learning of learners, but also affect the physical and mental health of learners. Therefore, in the MOOC era, teachers and students should seek a total of learning together. Research shows that the more experienced teachers are more willing to actively communicate with students, the easier for students to feel the presence of teachers.

Establish a Young Teacher Team for the Curriculum Development Vitality. As a new type of teaching skill, teachers 'information teaching ability is the core competence of teachers' professional development. It is the guarantee of teaching quality in colleges and universities, and should be paid more attention by universities and teachers. At the university level, we should increase the technical training and material support of the young teachers' informationization teaching ability. The development of MOOC human resources requires a vibrant team of teachers. Not every teacher is the right person, from the age structure point of view, young teachers should account for the main body of the teacher team. On the one hand the motive is the necessary prerequisite to plan to carry out, MOOC English teaching mode to change the traditional teaching mode, with decades of English teaching experience of the old teachers temporarily difficult to accept MOOC this fresh way of teaching. As now, in the multimedia widely used in the teaching of the era, many old teachers still choose to teach blackboard, handwriting lessons. The current young teachers are new human beings living in the cloud, living in micro-news, micro-blogging and other electronic media, and have stronger motives for the teaching mode based on electronic information technology. On the other hand, under normal circumstances young English teachers are highly educated cutting-edge talent, thinking avant-garde and their mental structure in line with MOOC development of the basic conditions. Although their teaching experience is not enough, but their memory, perception, imagination and so are at the peak of development, in the long-term acceptance of foreign culture under the influence of their fast knowledge, learning ability, creativity, so they are MOOC development of the most suitable candidates.

\section{Conclusion}

In summary, the emergence of MOOC to the traditional English teaching has brought great impact and impact. On the one hand, MOOC platform has emerged new educational resources to meet the learning needs of various students to promote the continuous development of students' personal English learning; on the other hand, MOOC combined with classroom teaching can overcome the shortcomings of traditional teaching Students' learning initiative, to ensure the continuity of classroom English learning after class. With the deepening of college English reform, it is worth exploring how to further develop MOOC courses and resources in a variety of ways to 
make them effective and classroom teaching.

\section{References}

[1] Cui Xieping, Wang Lanzhong. On the basis of MOOC's college English network teaching system [J]. Modern Educational Technology. 2015 (04)

[2] Yang Yang. MOOC in the development of excellence in English teachers in the application of path[J] .Jiaomusi Vocational College. 2015 (02)

[3] Wang Te. MOOC in the "cross-cultural communication" curriculum on cross-cultural communication ability of college students[J]. Shanxi Youth. 2016 (22)

[4] Zhang Guanyang. "MOOC" (Mu class) under the background of college English teaching innovation model [J]. Peer. 2016 (08)

[5] Shi Hengyang. Business simulation workshop MOOC curriculum design principles analysis[J] .Shenzhen Vocational and Technical College. 2016 (06)

[6] Li Wei. MOOC Mu class teaching in vocational college English teaching application [J] .Shi Fu era. 2015 (06) 